\title{
Effects of chronic exposure to bisphenol $A$ in adult female mice on social behavior, vasopressin system, and estrogen membrane receptor (GPER1)
}

\author{
Brigitta Bonaldo, ${ }^{1,2}$ Antonino Casile, ${ }^{1}$ Martina Bettarelli, ${ }^{1}$ Stefano Gotti, ${ }^{1,2}$ GianCarlo Panzica,, 2 \\ Marilena Marraudino ${ }^{1}$ \\ ${ }^{1}$ Neuroscience Institute Cavalieri Ottolenghi (NICO), Orbassano (TO) \\ ${ }^{2}$ Department of Neuroscience "Rita Levi-Montalcini", University of Turin, Italy
}

Bisphenol A (BPA), an organic synthetic compound found in some plastics and epoxy resins, is classified as an endocrine disrupting chemical. Exposure to BPA is especially dangerous if it occurs during specific "critical periods" of life, when organisms are more sensitive to hormonal changes (i.e., intrauterine, perinatal, juvenile or puberty periods). In this study, we focused on the effects of chronic exposure to BPA in adult female mice starting during pregnancy. Three months old C57BL/6J females were orally exposed to BPA or to vehicle (corn oil). The treatment ( $4 \mu \mathrm{g} / \mathrm{kg}$ body weight/day) started the day 0 of pregnancy and continued throughout pregnancy, lactation, and lasted for a total of 20 weeks. BPA-treated dams did not show differences in body weight or food intake, but they showed an altered estrous cycle compared to the controls. In order to evidence alterations in social and sociosexual behaviors, we performed the Three-Chamber test for sociability, and analyzed two hypothalamic circuits (well-known targets of endocrine disruption) particularly involved in the control of social behavior: the vasopressin and the oxytocin systems. The test revealed some alterations in the displaying of social behavior: BPA-treated dams have higher locomotor activity compared to the control dams, probably a signal of high level of anxiety. In addition, BPA-treated dams spent more time interacting with no-tester females than with no-tester males. In brain sections, we observed a decrease of vasopressin immunoreactivity (only in the paraventricular and suprachiasmatic nuclei) of BPA-treated females, while we did not find any alteration of the oxytocin system. In parallel, we have also observed, in the same hypothalamic nuclei, a significant reduction of the membrane estrogen receptor GPER1 expression.

Key words: Endocrine disrupting chemicals; BPA; Three-Chamber test; vasopressin, oxytocin; GPER1; paraventricular nucleus; suprachiasmatic nucleus.

Correspondence: Brigitta Bonaldo, Neuroscience Institute Cavalieri Ottolenghi (NICO), Regione Gonzole 10,10043 Orbassano (TO), Italy.

Tel. +39.011.6706632 - Fax:+39.011.2367054. E-mail: brigitta.bonaldo@unito.it

Conference Presentation: Preliminary results were presented during the XXX national meeting of the Italian Group for the Study of Neuromorphology (GISN).

Contributions: BB, designed and performed experiments, analyzed data and wrote the draft; $\mathrm{AC}, \mathrm{MB}$, performed experiments and analyzed data; SG, GCP, revised the draft and wrote the paper; MM, designed the experiment, revised the draft and wrote the paper.

Ethics approval: Animal care and handling were according to the European Union Council Directive of 22nd September 2010 (2010/63/UE). All the procedures reported in the present study were approved by the Italian Ministry of Health (407/2018-PR) and by the Ethical Committee of the University of Turin (Project $\mathrm{n}^{\circ} 360384$ ).

Conflict of interest: All authors have no conflicts of interest to declare with respect to the research, authorship, and/or publication of this article. 


\section{Introduction}

Thousands of chemicals, some banned and some still in use, have been classified as endocrine disruptor compounds (EDCs), i.e., exogenous chemicals, or mixture of chemicals, that can interfere with any aspect of hormone action. ${ }^{1}$ In particular, bisphenols (BPs), organic synthetic compounds largely used for the production of polycarbonate plastics and epoxy resins, are an extremely abundant class of EDCs. As reviewed by Catenza et al., ${ }^{2}$ the first synthesized BP, bisphenol A (BPA), has been utilized in the production of plastics since the 1950s. It is still the most highly produced BP: in 2018, about 7.2 million tons of BPA have been produced globally, and its consumption has been estimated to increase by 3.1 million tons by 2022. ${ }^{3,4}$ Thanks to its structure, BPA can interact with a wide set of hormone receptors both nuclear and membrane-bound, including estrogen receptors (ER $\alpha, E R \beta$, GPER1, ERR $\gamma$ ), androgen receptor, peroxisome proliferator-activated receptor $\gamma$, glucocorticoid receptors and thyroid hormone receptors. ${ }^{5,6}$ The capability of BPA to act through different types of receptors, differentially distributed in the tissues, is responsible for the wide range of effects it exerts on the organism. ${ }^{7} \mathrm{BPA}$, as other EDCs, is known to have organizational effects during development, and/or activational effects in adulthood. ${ }^{1}$ Exposure to EDCs is more dangerous if it occurs during specific "critical periods" of life, such as intrauterine, perinatal, juvenile or puberty periods, when organisms are more sensitive to hormonal action. ${ }^{8}$ Early pregnancy seems to be a particular sensitive period to BPA exposure, linked to the development of some adverse effects, such as intrauterine growth restriction. ${ }^{8}$ In addition, pregnancy, delivery and maternal care are highly regulated by hormonal actions. In fact, progesterone, prolactin and estradiol are involved in the organization and activation of brain area appointed to the control of these functions, such as the medial preoptic area (MePOA), the bed nucleus of stria terminalis (BST) and the medial amygdala $(\mathrm{MeA})$ which are enriched in estrogen, vasopressin and oxytocin receptors..$^{9,10}$

Vasopressin (AVP) and oxytocin (OXT) systems play a key role in the control of different type of behaviors, and in particular the maternal ${ }^{11}$ and the social one. ${ }^{12-15}$ They are two nonapeptides mainly synthesized in neurons of supraoptic (SON) and paraventricular (PVN) nuclei of the hypothalamus, and they, as well as their analogues in non-mammalian vertebrates, represent target systems underlying the alterations observed in social behavior after exposure to different types of EDCs. ${ }^{16-18}$ There are many studies, performed not only in rodents, which demonstrated that BPA exposure, mainly during pre- or peri-natal periods, is linked to alterations in both AVP and OXT number of neurons and innervation, especially in sexually dimorphic regions associated with social and aggressive behaviors and to anxiogenic effects. ${ }^{19}$

In the present study, we proposed pregnancy as a critical period not only for the developing fetus but also for the mother. We investigated the long-term consequences of chronic exposure to lowdose BPA, starting at mating and continuing throughout pregnancy and lactation, reaching 20 weeks of treatment, directly on the exposed dams. Primarily we focused on social behavior ${ }^{18}$ and on two of the circuits mainly involved in the control of this behavior, AVP and OXT, ${ }^{12-15}$ which are well-known targets of endocrine disruption, ${ }^{11,16,19}$ as well as the expression of the membrane estrogen receptor (GPER1) which is largely present in these nuclei. ${ }^{20}$

\section{Materials and Methods}

\section{Animals}

Adult C57BL/6J male and female mice from our outbred colony at the Neuroscience Institute Cavalieri Ottolenghi (originally purchased from Envigo, S. Pietro al Natisone, Udine, Italy) were housed in standard conditions in $45 \times 25 \times 15 \mathrm{~cm}$ polypropylene mouse cages at $22 \pm 2{ }^{\circ} \mathrm{C}$, under 12:12 light dark cycle (lights on at 8:00 am). Food and water were provided ad libitum (standard mouse chow 4RF21, Mucedola Srl, Settimo Milanese, Milan, Italy). One 3-months old male and two 3-months old female mice were caged together to achieve a successful mating, assessed by the evaluation of the presence of the vaginal plug (assumed as gestational day 0 , GD0).

\section{Treatment}

BPA (Sigma Aldrich, St. Louis, MO, USA; 239658, CAS 8005-7) was prepared for oral administration by dissolving it in corn oil (Sigma-Aldrich, C8267). 20 pregnant dams were divided into two experimental groups: control dams (receiving only vehicle, corn oil; $\mathrm{n}=10$ ) and treated dams (receiving $4 \mu \mathrm{g} / \mathrm{kg} \mathrm{BW} /$ day of BPA, corresponding to the European TDI; $n=10$ ).

Dams were treated started at GD0, throughout pregnancy and lactation, and continuing after the weaning of the offspring, for a total of 20 weeks of treatment. To mimic human exposure conditions, the daily treatment or the vehicle was given orally to the dams, with a pipette, in order to minimize the discomfort and the stress provoked to the dams during the treatment. ${ }^{21,22}$ The dose was calculated according to their body weight, recorded with an electronic precision balance (Mod. Kern-440-47N, resolution $0.1 \mathrm{~g}$ ).

We monitored the dams, evaluating in particular: i) body weight (BW), recorded daily; ii) after the weaning, the food intake (g of food/animal/day) once a week; iii) the estrous cycle, evaluating the vaginal cytology smears, ${ }^{23}$ after the $18^{\text {th }}$ week of treatment, for at least 2 cycles.

\section{Three-Chamber test}

Dams were tested after the $18^{\text {th }}$ week of treatment, in estrus phase (evaluated by vaginal smear). The test was conducted using a Three-Chamber social approach apparatus: a rectangular plastic box consisting of three same-sized chambers $(20 \mathrm{~cm} \times 25 \mathrm{~cm} \times 20$ $\mathrm{cm}$ ) with openings in the dividing walls that allowed the subject to access all three chambers without restriction. A plastic holding cylinder, for the novel and familiar mice, was placed in each of the side chambers. These cylinders were drilled to allow interactions between tester and no-tester mice.

Tester mice were placed in the room in which the test was performed at least $2 \mathrm{~h}$ before starting, to allow the habituation to room lighting. Before starting and between each session, the testing apparatus was cleaned with $70 \%$ ethanol, being sure to thoroughly dry the apparatus to avoid exposure of mice to alcohol. The testing procedure consisted of four chronological sessions: Habituation, two Sociability sessions, and Social preference. ${ }^{24}$ Each session lasted $5 \mathrm{~min}$ (schematic representation in Figure 1A) and at the end of each session the tester mouse was temporally moved to a clean housing cage while the investigator set up for the next session. As no-tester mice we selected unknown age-matched male or female C57BL/6J mice. In the habituation phase (Figure 1A, Session 1) the tester mouse was placed into the middle chamber and allowed to explore all three chambers freely. In the first sociability phase (Figure 1A, Session 2), an age- and gender-matched (female, in estrus phase) novel C57BL/6J mouse was placed into the holding cylinder placed in the right chamber. The same occurs in the second sociability phase (Figure 1A, Session 3), when an age- and 
A
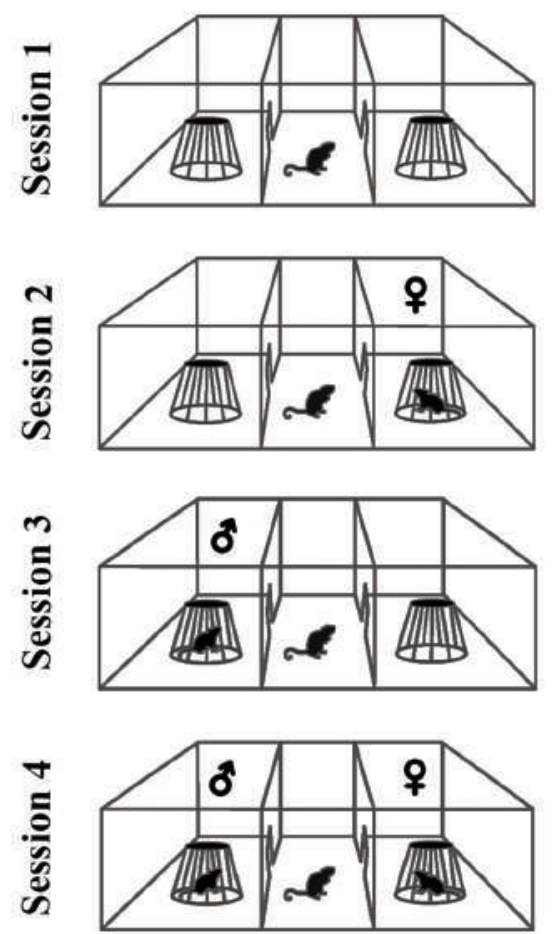

B
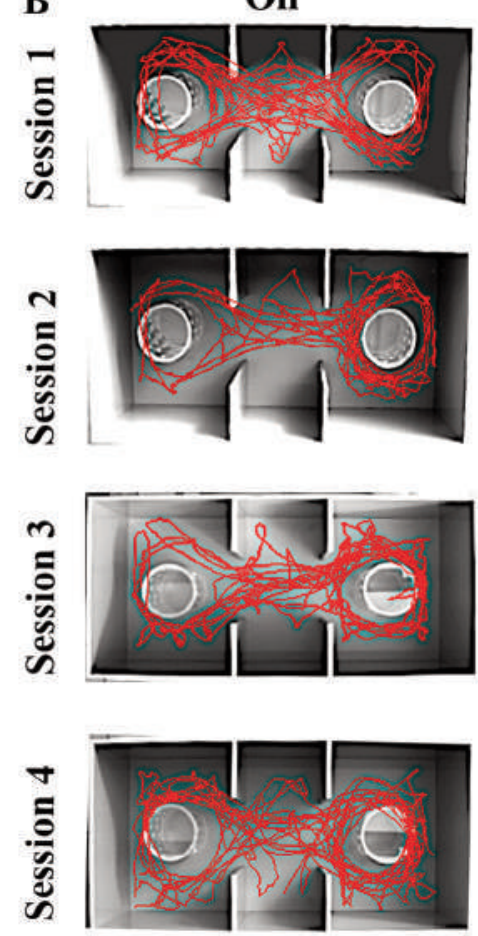

BPA
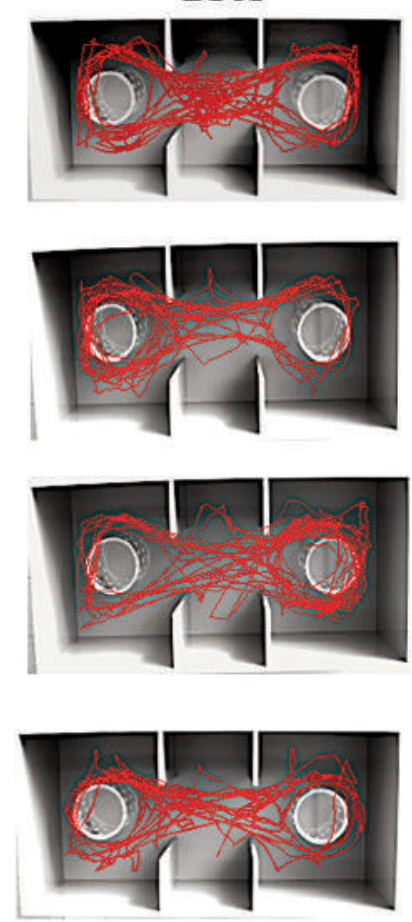

C

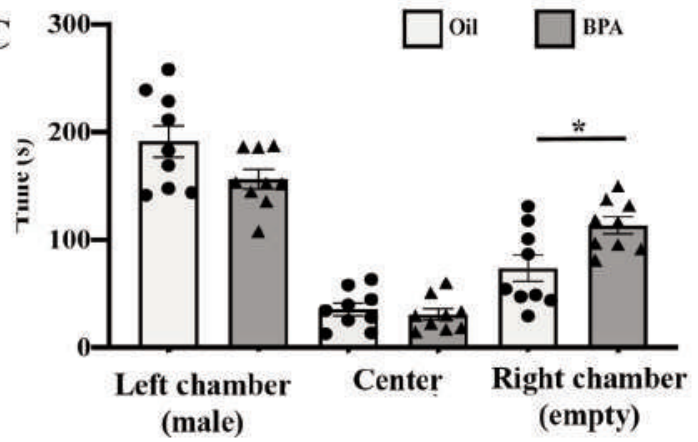

$\mathbf{E}$

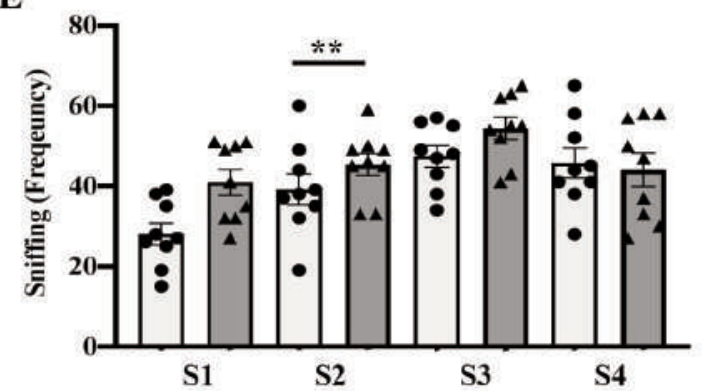

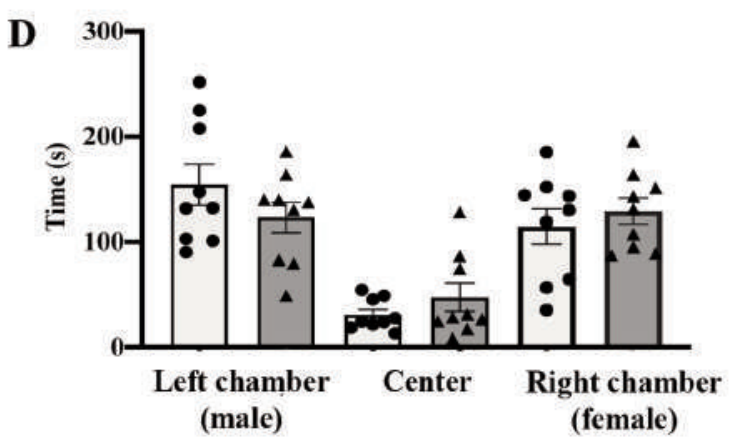

F

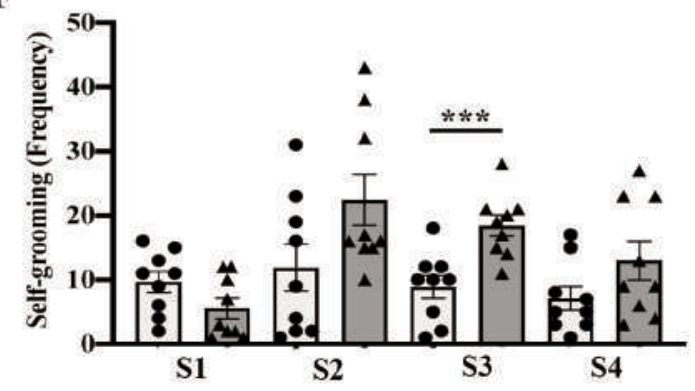

Figure 1. Analysis of social behavior of oil-treated and BPA-treated dams through Three-Chamber test. A) Experimental set-up and schematic representation of the apparatus used for the Three-Chamber test for the four experimental sessions: session 1 (habituation), session 2 (sociability with the gender-matched mouse), session 3 (sociability with the gender-mismatched mouse) and session 4 (social preference). B) Representative images for total distance traveled by Oil-treated dams (left column) or BPA-treated ones (right column) during the four sessions of the test. C,D) Time spent by the oil-treated (light gray) or BPA-treated (dark gray) dams within the three different chambers (left, center and right chamber) of the apparatus during $(C)$ the third session (sociability with gender-mismatched mouse) and (D) the fourth session (social preference) of the test. E,F) Frequency in sniffing (E) and grooming (F) behavior during the four sessions of the test displayed by the oil-treated (light gray) or BPA-treated (dark gray) dams. Data are expressed as mean \pm SEM. One-way ANOVA revealed a significant effect of the treatment for $\mathbf{p} \leq \mathbf{0 . 0 5}$. 
gender-mismatched (male) novel C57BL/6J mouse was presented to tester mouse in the holding cylinder placed in the left chamber. In the fourth and last session (Figure 1A, Session 4), the social preference was assessed, presenting to the tester mice both known female (right chamber) and male (left chamber) in the holding cylinder.

Each session was recorded with a camera placed above the apparatus in order to subsequently perform the behavioral analysis through the Ethovision XT program (Noldus Information Technology, Wageningen, The Netherlands). For each session we measured different parameters (listed above) in order to evaluated sex-dependent sociability, anxiety-related and explorative behaviors of the tester mouse:

- Distance: the total distance traveled $(\mathrm{cm})$ by the tester mice in each chamber and in the total arena.

Time: the time (s) spent in the different chambers by the tester mice.

Sniffing: the number of times and the time (s) spent by the tester mouse interacting with the no-tester mice in the holding cup or exploring the different chambers.

Self-grooming: the number of times and the time (s) spent by the tester mouse grooming itself.

Rearing: number of times and time (s) spent by the tester mouse rearing (i.e., the mouse is standing only on its posterior legs).

\section{Fixation and tissue sampling}

Dams were sacrificed after 20 weeks of treatment, in the estrus phase, assessed by vaginal smear, by deep irreversible anesthesia (intraperitoneal injection of zoletil $80 \mathrm{mg} / \mathrm{kg}$ / rompum $10 \mathrm{mg} / \mathrm{kg}$ ) and transcardially perfused with $4 \%$ paraformaldehyde (PFA) solution. Brains were removed and stored in a $4 \%$ PFA solution for $24 \mathrm{~h}$, followed by several washings in $0.01 \mathrm{M}$ saline phosphate buffer (PBS). Finally, they were stored in a 30\% sucrose solution in PBS at $4{ }^{\circ} \mathrm{C}$, frozen in isopentane pre-cooled in dry ice at $-35^{\circ} \mathrm{C}$ and stored in a deep freezer at $-80^{\circ} \mathrm{C}$ until sectioning. ${ }^{25}$

Brains ( $5 \pm 1$ /group) were serially cut in the coronal plane at 40 $\mu \mathrm{m}$ thickness with a cryostat, in four series. The plane of sectioning was oriented to match the drawings corresponding to the coronal sections of the mouse brain atlas. ${ }^{26}$ Sections were collected in a cryoprotectant solution ${ }^{27}$ and stored at $-20^{\circ} \mathrm{C}$. Three series were processed, for AVP, OXT and GPER1 immunohistochemistry, using the free-floating technique.

\section{Immunohistochemistry}

The presence of AVP, OXT, or GPER1 was detected by immunohistochemistry performed, according to our previous studies, ${ }^{20,25,28}$ on free-floating sections. Briefly, the sections were washed overnight in PBS at $\mathrm{pH}$ 7.3. The following day, sections were first washed in PBS containing $0.2 \%$ Triton X-100 for $30 \mathrm{~min}$ and then treated to inhibit endogenous peroxidase activity with a solution of PBS containing methanol/hydrogen peroxide for 20 min. Sections were then incubated for $30 \mathrm{~min}$ with normal goat serum (Vector Laboratories, Burlingame, CA, USA) and incubated overnight at room temperature with anti-AVP antibody (gift of Dr. Michael Sofroniew, UCLA, Los Angeles, CA, USA, Rabbit, $1: 20,000)^{29,30}$ or anti-OXT antibody (EMD Millipore AB911, Rabbit, 1:10,000) diluted in PBS, $\mathrm{pH} 7.3-7.4$, containing $0.2 \%$ Triton X-100. For GPER1 immunohistochemistry sections were washed for $30 \mathrm{~min}$ at room temperature in PBS containing $0.2 \%$ Triton X-100 and $0.2 \%$ BSA and then incubated $48 \mathrm{~h}$ at $4^{\circ} \mathrm{C}$ with anti-GPER-1 antibody (Abcam, Cambridge, UK, ab39742, Rabbit, $1: 250$ ) diluted in PBS containing $0.2 \%$ Triton X-100, 0.2\% BSA and $3 \%$ normal serum goat (Vector Laboratories). A biotinylated goat anti-rabbit secondary antibody (Vector Laboratories) was then employed at a dilution of 1:250 for $60 \mathrm{~min}$ at room temperature (dilution of 1:300 for $120 \mathrm{~min}$ at room temperature for GPER1). The antigen-antibody reaction was revealed by 60 (AVP and OXT) or 90 (for GPER1) min incubation with avidin-peroxidase complex (Vectastain ABC Kit Elite; Vector Laboratories). The peroxidase activity was visualized with a solution containing $0.400 \mathrm{mg} / \mathrm{ml}$ 3,3-diamino-benzidine (Sigma-Aldrich, Milan, Italy) and 0.004\% hydrogen peroxide in $0.05 \mathrm{M}$ Tris- $\mathrm{HCl}$ buffer at $\mathrm{pH}$ 7.6. Sections were mounted on chromallum-coated slides, air-dried, cleared in xylene and cover slipped with New-Entellan mounting medium (Merck, Milan, Italy). These antibodies were successfully used in previous studies. ${ }^{25,28,31-33}$ The specificity of these antisera was previously assessed, ${ }^{34-36}$ but, as a further control, we omitted the primary antiserum or the secondary biotinylated one, replaced with PBS. In both cases positive cell bodies and fibers were totally absent.

\section{Quantitative analysis}

For quantitative analysis, selected standardized sections of comparable levels covering the paraventricular nucleus (PVN, Bregma -0.58 to $-0.94 \mathrm{~mm}$ ), the supraoptic nucleus (SON, Bregma -0.58 to $-0.94 \mathrm{~mm}$ ), the suprachiasmatic nucleus ( $\mathrm{SCh}$, Bregma 0.34 to $-0.82 \mathrm{~mm}$ ) and the medial amygdala (MeA, Bregma -1.06 to $1.22 \mathrm{~mm}$ ) were chosen according to the mouse brain atlas. ${ }^{26}$ Two sections for each nucleus were acquired with a NIKON DS-U1 digital camera (Software of acquisition: NIS-Element AR 2.10) connected to a NIKON Eclipse 90i microscope (Nikon Italia S.p.A., Florence, Italy). Images were digitized by using a $20 \mathrm{x}$ objective. Digital images were processed and analyzed by ImageJ (v. 2.10/1.53c; Wayne Rasband, NIH, Bethesda, MD, USA). Measurements were performed within predetermined fields (region of interest, ROI), boxes of fixed size and shape that are inserted inside each labeled considered nucleus $\left(0.066 \mathrm{~mm}^{2}\right.$ for SON; $0.077 \mathrm{~mm}^{2}$ for SCh; $0.104 \mathrm{~mm}^{2}$ for MeA). The PVN was instead divided into subregions, following the different distribution within the nucleus of the two analyzed systems ${ }^{26}$ On one hand, for the AVP- immunoreactivity (ir) analysis, the PVN (total area 0.049 $\mathrm{mm}^{2}$ ) was divided into two sub-regions, the anterior parvicellular nucleus (PaAP, $0.013 \mathrm{~mm}^{2}$ ) and the ventral nucleus (PaV, 0.036 $\mathrm{mm}^{2}$ ). On the other hand, for the OXT-ir analysis, the PVN (total area $0.068 \mathrm{~mm}^{2}$ ) was divided in three subregions, the dorsal cap/lateral magnocellular part $\left(\mathrm{PaDC} / \mathrm{PaLM}, 0.013 \mathrm{~mm}^{2}\right)$, the medial parvicellular part (PaMP, $0.035 \mathrm{~mm}^{2}$ ) and the medial magnocellular part (PaMM, $\left.0.02 \mathrm{~mm}^{2}\right)$. Finally, the GPER1-ir was analyzed in the entire PVN.

We evaluated the extension of the immunoreactivity (cell bodies, dendrites, fibers) in all the selected nuclei as fractional area covered by immunopositive material. ${ }^{37}$ In addition, we counted the number of AVP-positive cells in PVN, SON and SCh, while the OXT-positive cells were counted in PVN and SON.

\section{Statistical analysis}

Quantitative data were examined with SPSS 26 statistic software (SPSS Inc., Chicago, USA) by one-way analysis of variance (ANOVA). Differences were considered statistically significant for values of $\mathrm{p} \leq 0.05$. Data are shown as mean \pm SEM (mean standard error).

\section{Results}

\section{Effects of chronic adult exposure to BPA on physiologi- cal parameters of the dams}

The performed treatment had not significant effects on body 
weight or food intake of the dams (data not shown). However, the estrous cycle of the BPA-exposed dams seems to be altered compared to the one of the control dams. In fact, the percentage of time spent in the estrus phase was significantly increased $(p=0.041)$ in the BPA-treated dams $(63.58 \pm 5.62 \%)$ compared to the controls $(44.34 \pm 5.91 \%)$.

\section{Three-Chamber test}

Results obtained from the analysis of the Three-Chamber test are summarized in Table 1 and Table 2, reporting all the values. Here we highlight the most interesting results (Figure 1), for each session:

Session 1 (Habituation). The total distance traveled by the BPA-treated dams was significantly higher compared to the controls $(\mathrm{p}=0.018)$ (Figure 1B). Furthermore, BPA dams also showed higher total sniffing behavior than controls $(\mathrm{p}=0.007)$ (Figure 1E).

Session 2 (Sociability with the gender-matched mouse). The total distance covered by the BPA-treated dams was, again, significantly higher compared to the controls $(p=0.006)$ (Figure $1 \mathrm{~B}$ ). Both groups preferred to spend time in the right chamber, where the female no-tester animal was placed, but, interestingly, BPAtreated dams did more sniffing compared to the controls $(\mathrm{p}=0.04)$ (Figure 1E).

Session 3 (Sociability with the gender-mismatched mouse). In this session, the distance covered by BPA-treated dams was significantly higher compared to the controls $(p=0.005)$ only in the left chamber, where the male no-tester animal was placed (Figure 1B).
Both BPA- and oil-treated dams preferred to spend the time in the left chamber, but the BPA-treated groups demonstrated a tendency to spend less time in this chamber compared to the control $(\mathrm{p}=0.058)$ (Figure 1C). Moreover, BPA-treated dams spent more time in the right chamber compared to the controls $(p=0.014)$ (Figure 1C). Besides, BPA-treated group did more grooming compared to the control $(\mathrm{p}=0.001)$, spending more time doing it $(\mathrm{p}=0.006)$ (Figure 1F).

Session 4 (Social preference). We did not find any significant differences in this last session. However, we noticed that difference of time spent in the two chambers was flattened in the BPA-treated group $(\mathrm{p}=0.759)$, showing no preference (Figure 1D). Moreover, the BPA-treated dams had a tendency $(\mathrm{p}=0.074)$ to spend less time sniffing the male no-tester mice compared to the controls (Figure 1E). Finally, the BPA-treated dams showed a tendency to do more rearing compared to the control $(\mathrm{p}=0.053)$, spending more time doing it $(\mathrm{p}=0.064)$.

\section{AVP-ir analysis}

The analysis of the AVP-ir (summarized in Table 3) revealed that the PVN (Figure $2 \mathrm{~A}-\mathrm{C}$ ) and the SCh (Figure 3) were affected by the treatment, whereas there was no effect on SON and MeA (Table 3).

In particular, we observed a significative reduction (Figure 2A) in both number of cells $(\mathrm{p}=0.005)$ (Figure $2 \mathrm{~B}$ ), and fractional area $(\mathrm{p}=0.036)$ (Figure $2 \mathrm{C})$ in the total PVN. This reduction is mainly due to the reduction of AVP-ir in the PaV of the BPA-treated group

Table 1. Results obtained from the analysis of the distance traveled and of the time spent in the total arena or different chambers of the Three-Chamber test. Data are reported as mean \pm SEM. One-way ANOVA revealed a significant effect of the treatment for $p \leq 0.05$.

\begin{tabular}{|c|c|c|c|c|}
\hline $\begin{array}{l}\text { Chamber } \\
\text { Parameter }\end{array}$ & Arena & $\begin{array}{c}\text { Left chamber } \\
\text { Session } 1 \text { (Habituation) }\end{array}$ & Center & Right chamber \\
\hline Distance traveled $(\mathrm{cm})$ & $\begin{array}{c}\text { Oil: } 86408.452 \pm 10979.28 \\
\text { BPA: } 126892.944 \pm 10764.76 \\
(p=0.018)\end{array}$ & $\begin{array}{l}\text { Oil: } 32590.944 \pm 4441.891 \\
\text { BPA: } 51877.389 \pm 5830.23 \\
\quad(p=0.018)\end{array}$ & $\begin{array}{c}\text { Oil: } 19823.03 \pm 2448.964 \\
\text { BPA: } 31452.311 \pm 3025.188 \\
(p=0.009)\end{array}$ & $\begin{array}{c}\text { Oil: } 3394.478 \pm 4713.435 \\
\text { BPA: } 43563.244 \pm 3842.471 \\
(p=0.135)\end{array}$ \\
\hline Time (s) & $\begin{array}{l}\text { Oil: } 300.181 \pm 0.035 \\
\text { BPA: } 300.11 \pm 0.03 \\
\quad(p=0.153)\end{array}$ & $\begin{array}{l}\text { Oil: } 112.626 \pm 7.141 \\
\text { BPA: } 112.076 \pm 7.272 \\
\quad(p=0.958)\end{array}$ & $\begin{array}{c}\text { Oil: } 78.492 \pm 5.561 \\
\text { BPA: } 62.311 \pm 5.031 \\
\quad(p=0.046)\end{array}$ & $\begin{array}{l}\text { Oil: } 109.063 \pm 6.56 \\
\text { BPA: } 125.724 \pm 10.482 \\
\quad(p=0.197)\end{array}$ \\
\hline \multicolumn{5}{|c|}{ Session 2 (Sociability with no-tester female) } \\
\hline Distance traveled $(\mathrm{cm})$ & $\begin{array}{l}\text { Oil: } 83438.054 \pm 12399.336 \\
\text { BPA: } 137443.87 \pm 11607.57 \\
\quad(p=0.006)\end{array}$ & $\begin{array}{c}\text { Oil: } 41711.411 \pm 6090.7754 \\
\text { BPA: } 66523 \pm 7443.3324 \\
(p=0.02)\end{array}$ & $\begin{array}{l}\text { Oil: } 21088.391 \pm 3296.322 \\
\text { BPA: } 36700.822 \pm 3511.7 \\
\quad(p=0.005)\end{array}$ & $\begin{array}{c}\text { Oil: } 20638.252 \pm 4315.31 \\
\text { BPA: } 34220.044 \pm 3806.443 \\
(p=0.031)\end{array}$ \\
\hline Time (s) & $\begin{array}{l}\text { Oil: } 300.197 \pm 0.041 \\
\text { BPA: } 300.111 \pm 0.031 \\
\quad(p=0.116)\end{array}$ & $\begin{array}{l}\text { Oil: } 71.936 \pm 8.824 \\
\text { BPA: } 92.209 \pm 12.174 \\
\quad(p=0.196)\end{array}$ & $\begin{array}{c}\text { Oil: } 52.725 \pm 5.93 \\
\text { BPA: } 37.272 \pm 4.22 \\
\quad(p=0.049)\end{array}$ & $\begin{array}{l}\text { Oil: } 175.509 \pm 12.648 \\
\text { BPA: } 170.63 \pm 12.226 \\
\quad(p=0.785)\end{array}$ \\
\hline \multicolumn{5}{|c|}{ Session 3 (Sociability with no-tester male) } \\
\hline Distance traveled $(\mathrm{cm})$ & $\begin{array}{c}\text { Oil: } 111206.4 \pm 17506.127 \\
\text { BPA: } 124788.84 \pm 15582.89 \\
(p=0.57)\end{array}$ & $\begin{array}{c}\text { Oil: } 19509.378 \pm 2115.5327 \\
\text { BPA: } 40075.422 \pm 6023.7911 \\
(p=0.05)\end{array}$ & $\begin{array}{c}\text { Oil: } 30649.682 \pm 5578.267 \\
\text { BPA: } 33305.933 \pm 4539.924 \\
\quad(p=0.717)\end{array}$ & $\begin{array}{c}\text { Oil: } 61047.344 \pm 12048.584 \\
\text { BPA: } 51407.489 \pm 6711.153 \\
(p=0.495)\end{array}$ \\
\hline Time (s) & $\begin{array}{c}\text { Oil: } 300.158 \pm 0.04 \\
\text { BPA: } 300.138 \pm 0.038 \\
\quad(p=0.722)\end{array}$ & $\begin{array}{l}\text { Oil: } 191.422 \pm 14.775 \\
\text { BPA: } 156.247 \pm 8.873 \\
(p=0.058)^{*}\end{array}$ & $\begin{array}{l}\text { Oil: } 35.453 \pm 5.911 \\
\text { BPA: } 30.607 \pm 5.213 \\
(p=0.547)\end{array}$ & $\begin{array}{c}\text { Oil: } 73.281 \pm 12.224 \\
\text { BPA: } 113.283 \pm 7.809 \\
(p=0.014)\end{array}$ \\
\hline \multicolumn{5}{|c|}{ Session 4 (Social preference) } \\
\hline Distance traveled $(\mathrm{cm})$ & $\begin{array}{c}\text { Oil: } 110284.94 \pm 15934.653 \\
\text { BPA: } 124198.21 \pm 17361.655 \\
(p=0.563)\end{array}$ & $\begin{array}{l}\text { Oil: } 33876.808 \pm 6436.024 \\
\text { BPA: } 47583.567 \pm 8235.806 \\
\quad(p=0.208)\end{array}$ & $\begin{array}{c}\text { Oil: } 31700.611 \pm 5075.1257 \\
\text { BPA: } 33132.369 \pm 5619.05 \\
\quad(p=0.852)\end{array}$ & $\begin{array}{c}\text { Oil: } 44707.522 \pm 8985.061 \\
\text { BPA: } 43482.278 \pm 7476.7306 \\
(p=0.918)\end{array}$ \\
\hline Time (s) & $\begin{array}{l}\text { Oil: } 300.181 \pm 0.035 \\
\text { BPA: } 300.137 \pm 0.038 \\
(p=0.413)\end{array}$ & $\begin{array}{c}\text { Oil: } 154.534 \pm 19.698 \\
\text { BPA: } 123.32 \pm 14.641 \\
(p=0.222)\end{array}$ & $\begin{array}{c}\text { Oil: } 30.981 \pm 4.9 \\
\text { BPA: } 47.487 \pm 13.349 \\
(p=0.263)\end{array}$ & $\begin{array}{c}\text { Oil: } 114.666 \pm 16.898 \\
\text { BPA: } 129.33 \pm 12.524 \\
(p=0.496)\end{array}$ \\
\hline
\end{tabular}

*Tendency towards significance $(0.05<\mathrm{p}<0.06)$. 
compared to the controls (cell number, $\mathrm{p}<0.005$, fractional area, $\mathrm{p}<0.043)$. Also, in the SCh we observed a significant reduction in the BPA-treated group (Figure 3A) of AVP-ir in both number of cells $(p=0.002)$ (Figure 3B) and fractional area $(p=0.004)$ (Figure 3C).

The analysis of both number of cells and fractional area revealed no effects of the treatment in the $\mathrm{SON}$, as well as in the $\mathrm{MeA}$.

\section{OXT-ir analysis}

The analysis of the OXT-ir did not show any significant difference between groups in the analyzed nuclei (Table 3 ).

In particular, we did not observe any difference in the total PVN (Figure 2D), both in number of cells $(\mathrm{p}=0.806)$ (Figure 2E) and fractional area $(\mathrm{p}=0.548)$ (Figure $2 \mathrm{~F})$. Moreover, the further analysis of the PVN subnuclei (PaDC/PaLM, PaMP, PaMM) confirmed the absence of effects of treatment on OXT-ir: in fact, the two experimental groups also maintained the same distribution of the OXT-ir within the subnuclei, both for the number of cells (PaDC/PALM, $\mathrm{p}=0.557$, PaMP, $\mathrm{p}=0.967$. PaMM, $\mathrm{p}=0.888$ ) (Figure 2E) and the fractional area (PaDC/PALM, $\mathrm{p}=0.349$. PaMP, $\mathrm{p}=0.678$. PaMM, $\mathrm{p}=0.588$ ) (Figure 2F).

The treatment did not affect the OXT-ir in the SON and in the MeA (Table 3).

\section{GPER1-ir analysis}

We performed the quantitative analysis for GPER1-ir in all analyzed nuclei (Table 3 ). This analysis revealed a significant effect of the treatment only in PVN and SCh, the nuclei in which we observed also significant changes in AVP-ir. In particular, we observed a significative reduction (Figure 4) in GPER1-ir in terms of fractional area both in PVN (Figure 4 A,B) $(\mathrm{p}<0.001)$ and in $\mathrm{SCh}$ (Figure $4 \mathrm{C})(\mathrm{p}=0.003)$ in the BPA-treated animals compared to the control ones.

\section{Discussion}

The results of this study support the idea that pregnancy represents a particularly sensitive period of adult life for endocrine disruption and that the continued exposure to BPA could lead to behavioral and neuroendocrine circuits alterations not only in the offspring but also in the exposed dams. In fact, we observed some alterations in the displaying of social behavior, although BPAtreated dams did not lose the sociability skills. Interestingly BPAtreated dams demonstrated higher interactions towards no tester female and lower interactions toward the male one compared to the control dams. The analysis of two systems strongly correlated to the control of social behavior, vasopressin and oxytocin hypothal-

Table 2. Results obtained from the analysis of different behaviors (sniffing, grooming, rearing, escape) during the four sessions of the Three-chamber test. Data are reported as mean \pm SEM, both as frequency $(F)$ and cumulative duration $(C D)$. One-way ANOVA revealed a significant effect of the treatment for $\mathrm{p} \leq \mathbf{0 . 0 5}$.

\begin{tabular}{|c|c|c|c|c|}
\hline Parameter & Session 1 & Session 2 & Session 3 & Session 4 \\
\hline Sniffing in left chamber (F) & $\begin{array}{c}\text { Oil: } 11.556 \pm 2.304 \\
\text { BPA: } 20.889 \pm 3.442 \\
\quad(p=0.039)\end{array}$ & $\begin{array}{c}\text { Oil: } 23 \pm 4.69 \\
\text { BPA: } 19.222 \pm 2.645 \\
\quad(p=0.493)\end{array}$ & $\begin{array}{c}\text { Oil: } 23.778 \pm 2.666 \\
\text { BPA: } 24.667 \pm 1.763 \\
\quad(p=0.784)\end{array}$ & $\begin{array}{c}\text { Oil: } 19.444 \pm 2.982 \\
\text { BPA: } 24 \pm 3.742 \\
\quad(p=0.355)\end{array}$ \\
\hline Sniffing in left chamber (CD) & $\begin{array}{c}\text { Oil: } 14.406 \pm 6.052 \\
\text { BPA: } 24.374 \pm 7.767 \\
\quad(p=0.326)\end{array}$ & $\begin{array}{l}\text { Oil: } 28.382 \pm 9.533 \\
\text { BPA: } 20.507 \pm 4.379 \\
\quad(p=0.464)\end{array}$ & $\begin{array}{c}\text { Oil: } 28.139 \pm 5.012 \\
\text { BPA: } 25.218 \pm 5.88 \\
\quad(p=0.71)\end{array}$ & $\begin{array}{c}\text { Oil: } 22.754 \pm 5.103 \\
\text { BPA: } 28.824 \pm 6.332 \\
\quad(p=0.446)\end{array}$ \\
\hline Sniffing in right chamber (F) & $\begin{array}{c}\text { Oil: } 16.444 \pm 2.9 \\
\text { BPA: } 20 \pm 3.202 \\
\quad(p=0.422)\end{array}$ & $\begin{array}{l}\text { Oil: } 16.222 \pm 3.122 \\
\text { BPA: } 26.222 \pm 3.205 \\
\quad(p=0.04)\end{array}$ & $\begin{array}{c}\text { Oil: } 23.667 \pm 2.744 \\
\text { BPA: } 29.778 \pm 3.403 \\
\quad(p=0.181)\end{array}$ & $\begin{array}{c}\text { Oil: } 26.333 \pm 3.693 \\
\text { BPA: } 20.111 \pm 1.495 \\
\quad(p=0.138)\end{array}$ \\
\hline Sniffing in right chamber (CD) & $\begin{array}{c}\text { Oil: } 15.296 \pm 3.934 \\
\text { BPA: } 17.696 \pm 4.013 \\
\quad(p=0.675)\end{array}$ & $\begin{array}{c}\text { Oil: } 15.013 \pm 4.427 \\
\text { BPA: } 28.142 \pm 5.49 \\
\quad(p=0.081)\end{array}$ & $\begin{array}{l}\text { Oil: } 25.64 \pm 4.322 \\
\text { BPA: } 28.64 \pm 4.442 \\
\quad(p=0.635)\end{array}$ & $\begin{array}{c}\text { Oil: } 30.39 \pm 6.766 \\
\text { BPA: } 16.886 \pm 2.062 \\
\quad(p=0.074)\end{array}$ \\
\hline Total sniffing (F) & $\begin{array}{c}\text { Oil: } 28 \pm 2.724 \\
\text { BPA: } 40.889 \pm 3.203 \\
\quad(p=0.007)\end{array}$ & $\begin{array}{c}\text { Oil: } 39.222 \pm 3.792 \text { B } \\
\text { PA: } 45.444 \pm 2.739 \\
\quad(p=0.202)\end{array}$ & $\begin{array}{c}\text { Oil: } 47.444 \pm 2.672 \\
\text { BPA: } 54.444 \pm 3.096 \\
\quad(p=0.089)\end{array}$ & $\begin{array}{c}\text { Oil: } 45.778 \pm 3.696 \\
\text { xBPA: } 44.111 \pm 4.185 \\
\quad(p=0.769)\end{array}$ \\
\hline Total sniffing (CD) & $\begin{array}{c}\text { Oil: } 29.702 \pm 6.396 \\
\text { BPA: } 42.072 \pm 7.248 \\
\quad(p=0.219)\end{array}$ & $\begin{array}{c}\text { Oil: } 43.396 \pm 8.201 \\
\text { BPA: } 48.649 \pm 5.579 \\
\quad(p=0.604)\end{array}$ & $\begin{array}{c}\text { Oil: } 53.779 \pm 4.394 \\
\text { BPA: } 53.858 \pm 5.868 \\
\quad(p=0.992)\end{array}$ & $\begin{array}{c}\text { Oil: } 53.144 \pm 6.394 \\
\text { BPA: } 45.710 \pm 6.386 \\
\quad(p=0.423)\end{array}$ \\
\hline Grooming (F) & $\begin{array}{c}\text { Oil: } 9.667 \pm 1.616 \\
\text { BPA: } 5.556 \pm 1.573 \\
\quad(p=0.087)\end{array}$ & $\begin{array}{l}\text { Oil: } 11.889 \pm 3.615 \\
\text { BPA: } 22.444 \pm 3.969 \\
\quad(p=0.067)\end{array}$ & $\begin{array}{l}\text { Oil: } 8.889 \pm 1.791 \\
\text { BPA: } 18.444 \pm 1.651 \\
\quad(p=0.001)\end{array}$ & $\begin{array}{l}\text { Oil: } 7.111 \pm 1.829 \\
\text { BPA: } 13 \pm 3.023 \\
\quad(p=0.115)\end{array}$ \\
\hline Grooming (CD) & $\begin{array}{c}\text { Oil: } 18.911 \pm 2.250 \\
\text { BPA: } 11.991 \pm 4.758 \\
\quad(p=0.207)\end{array}$ & $\begin{array}{c}\text { Oil: } 17.102 \pm 5.858 \\
\text { BPA: } 32.649 \pm 5.845 \\
\quad(p=0.079)\end{array}$ & $\begin{array}{c}\text { Oil: } 9.131 \pm 2.402 \\
\text { BPA: } 20.64 \pm 2.787 \\
\quad(p=0.006)\end{array}$ & $\begin{array}{c}\text { Oil: } 11.697 \pm 2.935 \\
\text { BPA: } 21.738 \pm 9.423 \\
\quad(p=0.324)\end{array}$ \\
\hline Rearing (F) & $\begin{array}{c}\text { Oil: } 13.889 \pm 1.798 \\
\text { BPA: } 17.667 \pm 4.794 \\
\quad(p=0.408)\end{array}$ & $\begin{array}{c}\text { Oil: } 4.333 \pm 1.75 \\
\text { BPA: } 7.556 \pm 3.72 \\
\quad(p=0.421)\end{array}$ & $\begin{array}{c}\text { Oil: } 10.333 \pm 2.635 \\
\text { BPA: } 11 \pm 2.217 \\
(p=0.849)\end{array}$ & $\begin{array}{c}\text { Oil: } 5.222 \pm 1.176 \\
\text { BPA: } 9.111 \pm 1.448 \\
\quad(p=0.053)^{*}\end{array}$ \\
\hline Rearing (CD) & $\begin{array}{c}\text { Oil: } 14.74 \pm 2.692 \\
\text { BPA: } 17.908 \pm 4.794 \\
\quad(p=0.573)\end{array}$ & $\begin{array}{l}\text { Oil: } 3.92 \pm 1.75 \\
\text { BPA: } 5.742 \pm 2.678 \\
\quad(p=0.577)\end{array}$ & $\begin{array}{c}\text { Oil: } 9.584 \pm 3.055 \\
\text { BPA: } 8.284 \pm 1.488 \\
\quad(p=0.707)\end{array}$ & $\begin{array}{c}\text { Oil: } 3.06 \pm 0.993 \\
\text { BPA: } 6.283 \pm 1.282 \\
\quad(p=0.064)\end{array}$ \\
\hline
\end{tabular}

*Tendency towards significance $(0.05<\mathrm{p}<0.06)$. 
amic systems, highlighted alterations in the AVP-ir in the hypothalamic paraventricular and suprachiasmatic nuclei, while we did not find any alteration in the oxytocin system. In addition, the subsequent analysis of the GPER1-ir in PVN and SCh, revealed a significative reduction of the signal in the BPA-treated dams compared to the control ones.

Rodents are social animals, they not only live in groups, perceiving isolation as a great stress, but they are also engaged in a wide variety of social behaviors throughout life. ${ }^{18}$ Therefore, alterations in the social skills due to EDCs exposure may have very serious implications on the quality of life of those animals, impacting different aspects of their social lives and altering their response to other animals and to the environment. ${ }^{18}$ Social behavior is a well-known target of endocrine disruption and specifically of BPA exposure, in particular during pre- and peri-natal periods, led to alterations in adult social and sociosexual behaviors in several species. ${ }^{18,38}$ However, in the literature, there are few works highlighting the behavioral effects of chronic exposure to BPA during adulthood in female mice, as most of them focus on different exposure and targets, and are mainly performed in rats. ${ }^{39-41}$ Our results

Table 3. Results obtained from the analysis of AVP-ir, OXT-ir and GPER1-ir in all the selected nuclei. Data are reported as mean \pm SEM, both, when possible, as number of positive cells and fractional area. One-way ANOVA revealed a significant effect of the treatment for $\mathbf{p} \leq \mathbf{0 . 0 5}$.

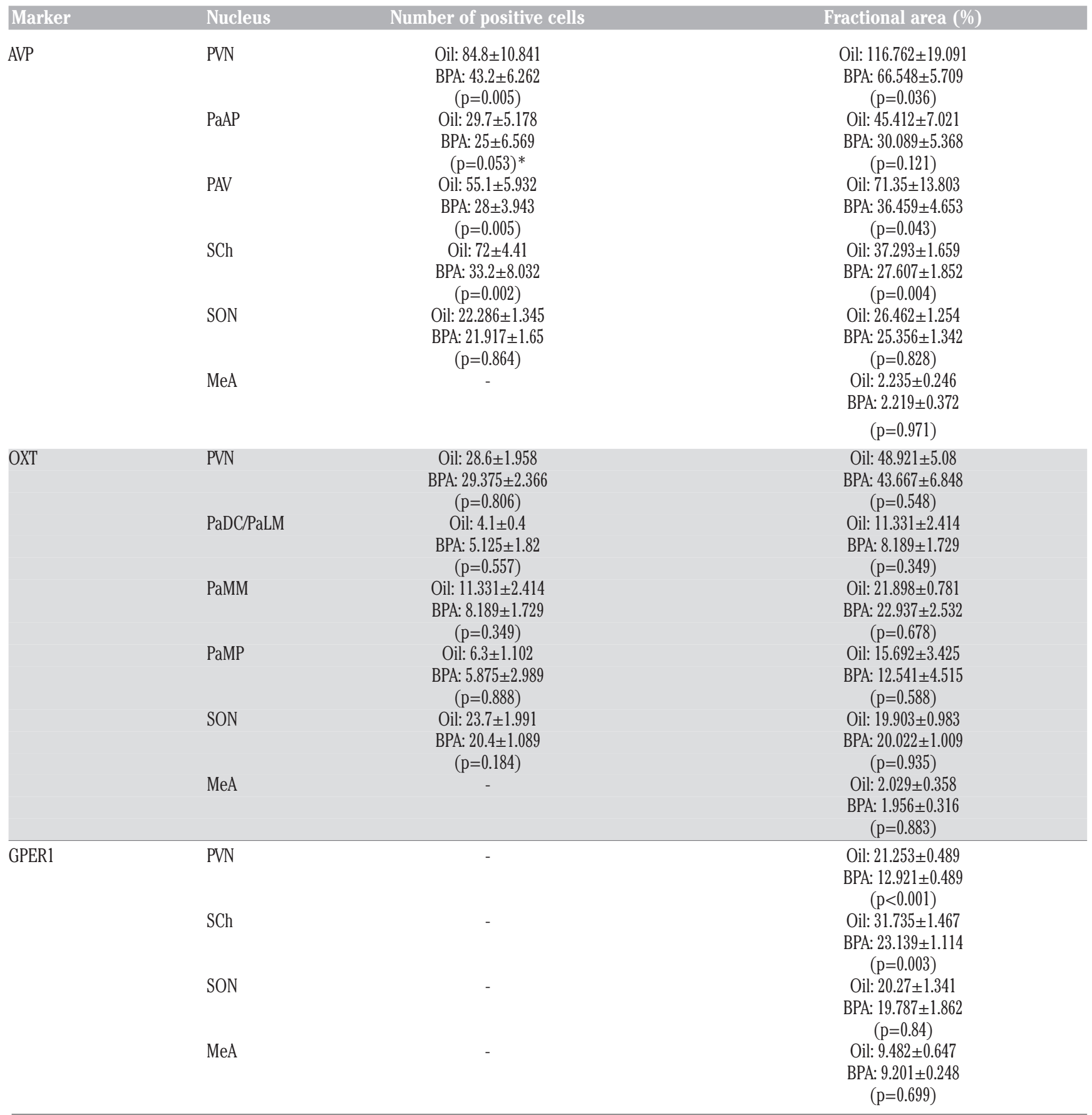

\footnotetext{
${ }^{*}$ Tendency towards significance $(0.05<\mathrm{p}<0.06)$.
} 
support the idea that BPA exposure led to alterations in the displaying of social behavior, even when it occurs in adult life. The analysis of sex-driven social behavior through the Three-Chamber test highlighted some alterations in the BPA-treated dams. The higher distance traveled displayed by the BPA-treated dams during the test indicates a higher locomotor activity compared to the control dams that could be due to a higher level of anxiety. In the literature, it has been demonstrated that exposure to BPA can cause alterations in the anxiety state in rodents. ${ }^{39}$ In particular, BPA exposure is associated to increased anxiety-like behavior in rodents, ${ }^{19}$ not
A

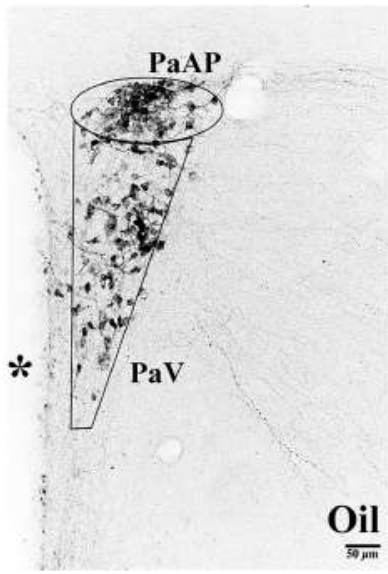

B

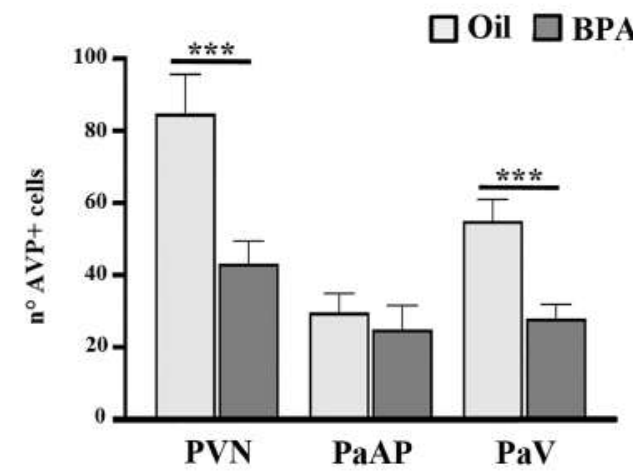

C

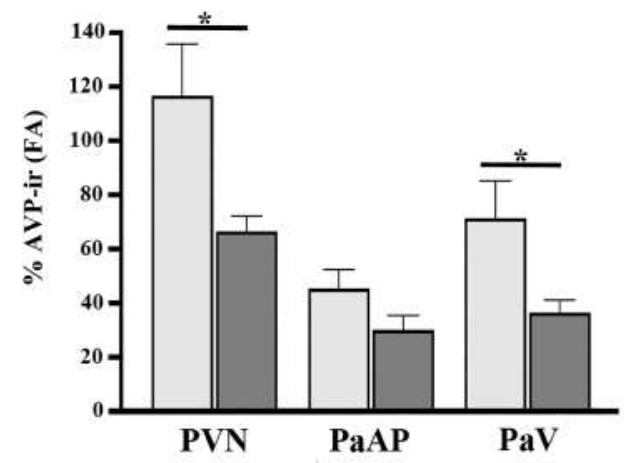

AVP D
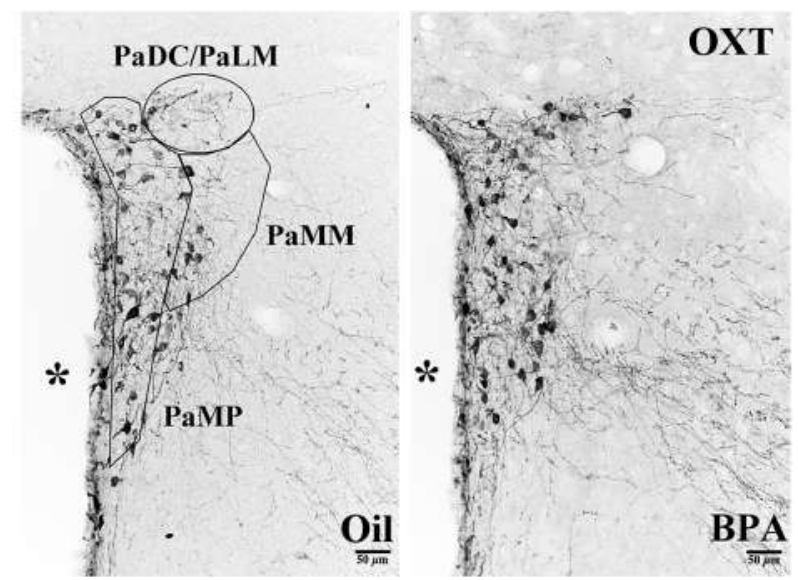

$\mathbf{E}$

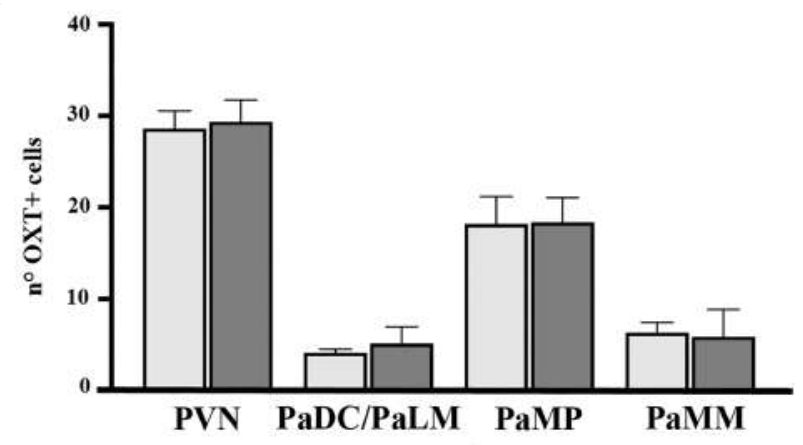

F

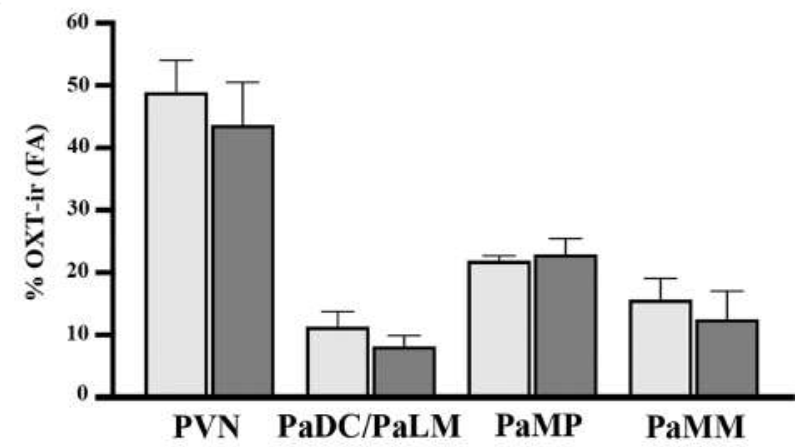

Figure 2. AVP-ir and OXT-ir in the PVN of oil-treated and BPA-treated dams. A) Representative image of AVP-ir in a coronal section of PVN of oil-treated (left images) or BPA-treated (right images) dams. Analysis of AVP-ir in PVN, expressed both as (B) number of AVP positive cells and (C) fractional area (FA), revealed a significant reduction in BPA-treated dams (dark gray) compared to the control ones (light gray), mainly due to the ventral component of the nucleus $(\mathrm{PaV})$. D) Representative image of oxytocin signal in a coronal section of PVN of oil-treated (left images) or BPA-treated (right images) dams. Analysis of OXT-ir in PVN, expressed both as (E) number of OXT positive cells and (F) fractional area (FA), in oil-treated (light gray) and BPA-treated (dark gray) dams did not show any effect link to the treatment. Data are expressed as mean \pm SEM. One-way ANOVA revealed a significant effect of the treatment for $p \leq 0.05$. AVP, vasopressin; OXT, oxytocin; PVN, paraventricular nucleus; PaAP, anterior parvicellular nucleus; PaV, ventral nucleus; PaDC/PaLM, dorsal cap/lateral magnocellular part; PaMP, medial parvicellular part; PaMM, medial magnocellular part; FA, fractional area; *third ventricle. 
only when the exposure occurred during the perinatal period, ${ }^{42}$ but also in adulthood. ${ }^{43}$ Long-term oral exposure to BPA during adulthood is associated with alterations of anxiety-related behaviors mainly in male mice. ${ }^{43}$ Interestingly, our treatment highlighted the fact that also female mice can be affected by anxiety-related behavioral changes when the chronic exposure involved the sensitive periods of pregnancy and lactation. Moreover, the two socia- bility sessions showed that BPA-treated dams did not lose the sociability skills, spending in both sessions more time in the chamber with the no-tester animals. However, BPA-treated dams have shown a tendency $(\mathrm{p}=0.058)$ to interact (higher sniffing behavior) more with the no-tester female compared to the controls, suggesting that they have no interest in interacting with the male. In the last session, the lack of sex-dependent social preference was more
A

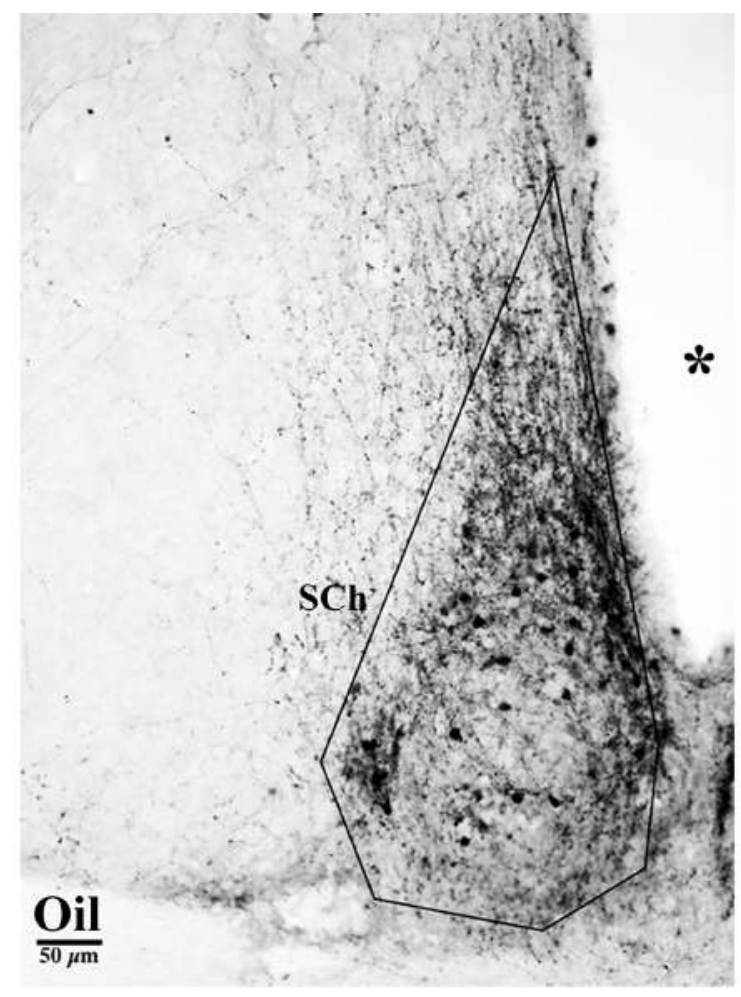

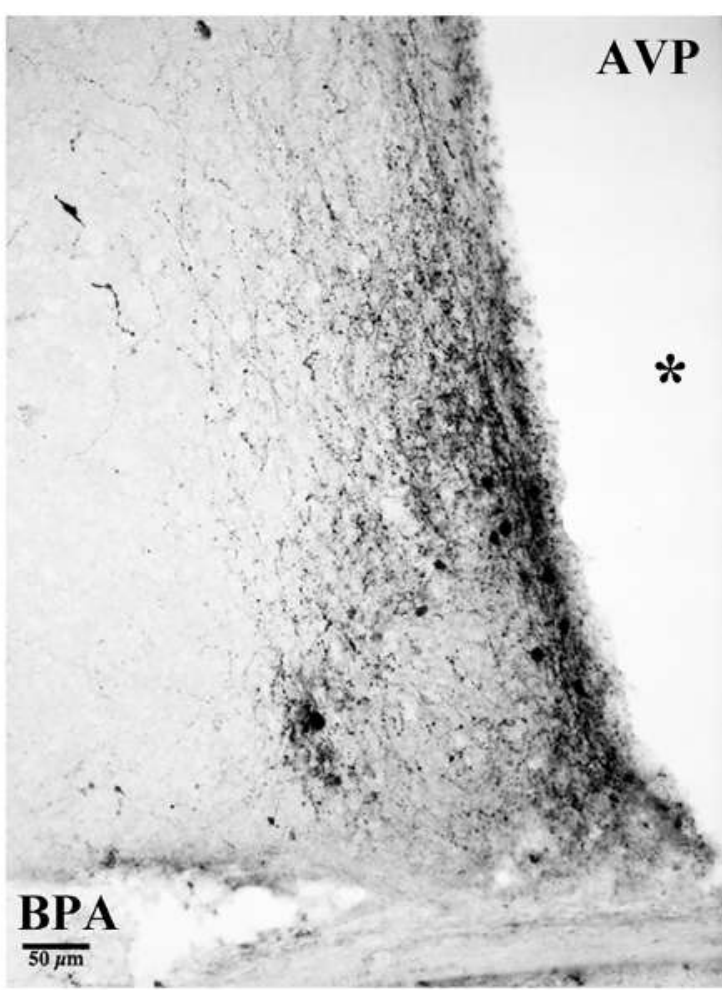

B

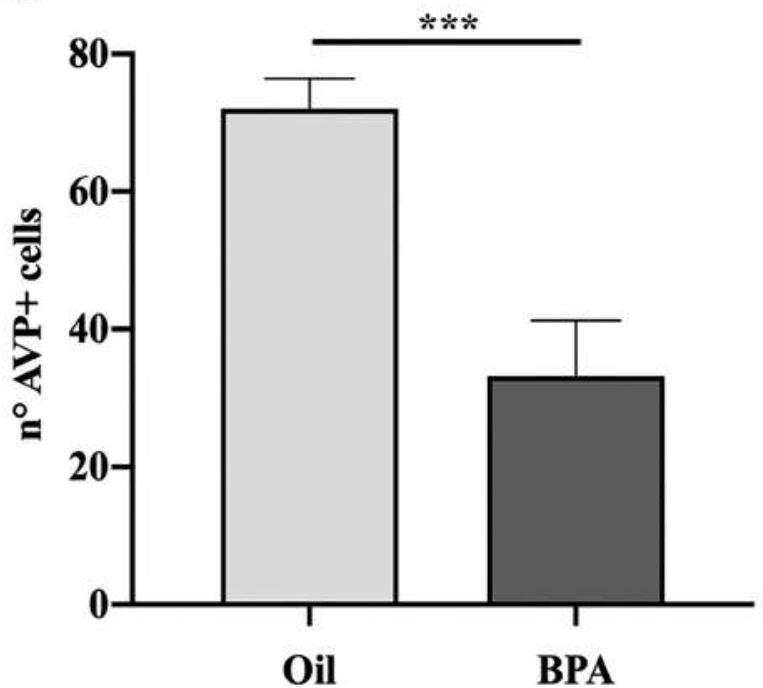

C

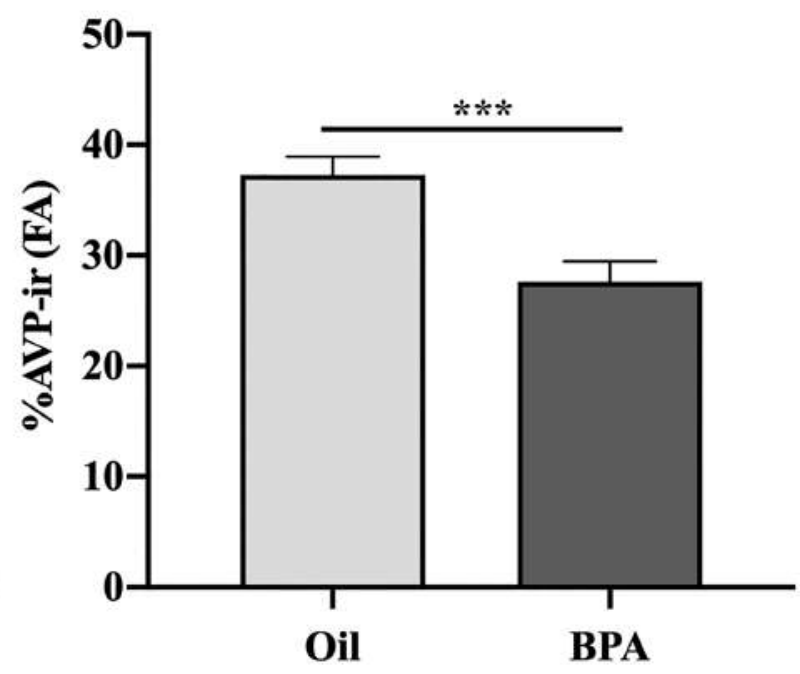

Figure 3. AVP-ir in the SCh of oil-treated and BPA-treated dams. A) Representative image of AVP-ir in a coronal section of SCh of oiltreated (left images) or BPA-treated (right images) dams. Analysis of AVP-ir in SCh, expressed both as (B) number of AVP positive cells and (C) fractional area (FA), revealed a significant reduction in BPA-treated dams (dark gray) compared to the control ones (light gray). Data are expressed as mean \pm SEM. One-way ANOVA revealed a significant effect of the treatment for $\mathrm{p} \leq 0.05$. AVP, vasopressin; OXT, oxytocin; SCh, suprachiasmatic nucleus; FA, fractional area; *third ventricle. 
evident in the BPA-treated group, and it seems to be even more evident towards the male no-tester mouse. Previous studies performed in rodents have demonstrated that different kinds of exposure to BPA cause different alterations in the social and socio-sexual behavior: in particular, the interactions between same-sex and opposite-sex no-tester animal seems to be differentially affected..$^{18,19}$ These studies suggest that the alterations in social behavior linked to BPA exposure and alterations in mechanisms which are involved also in sexual preference and behavior could come together. ${ }^{2,44,45}$ Furthermore, it is known that olfactory discrimination, which is fundamental in both social and sexual behavior, can be altered by BPA exposure. ${ }^{45,46}$

Vasopressin and oxytocin systems play a key role in the control of social behavior. ${ }^{13,15}$ They have been therefore recognized as the
A
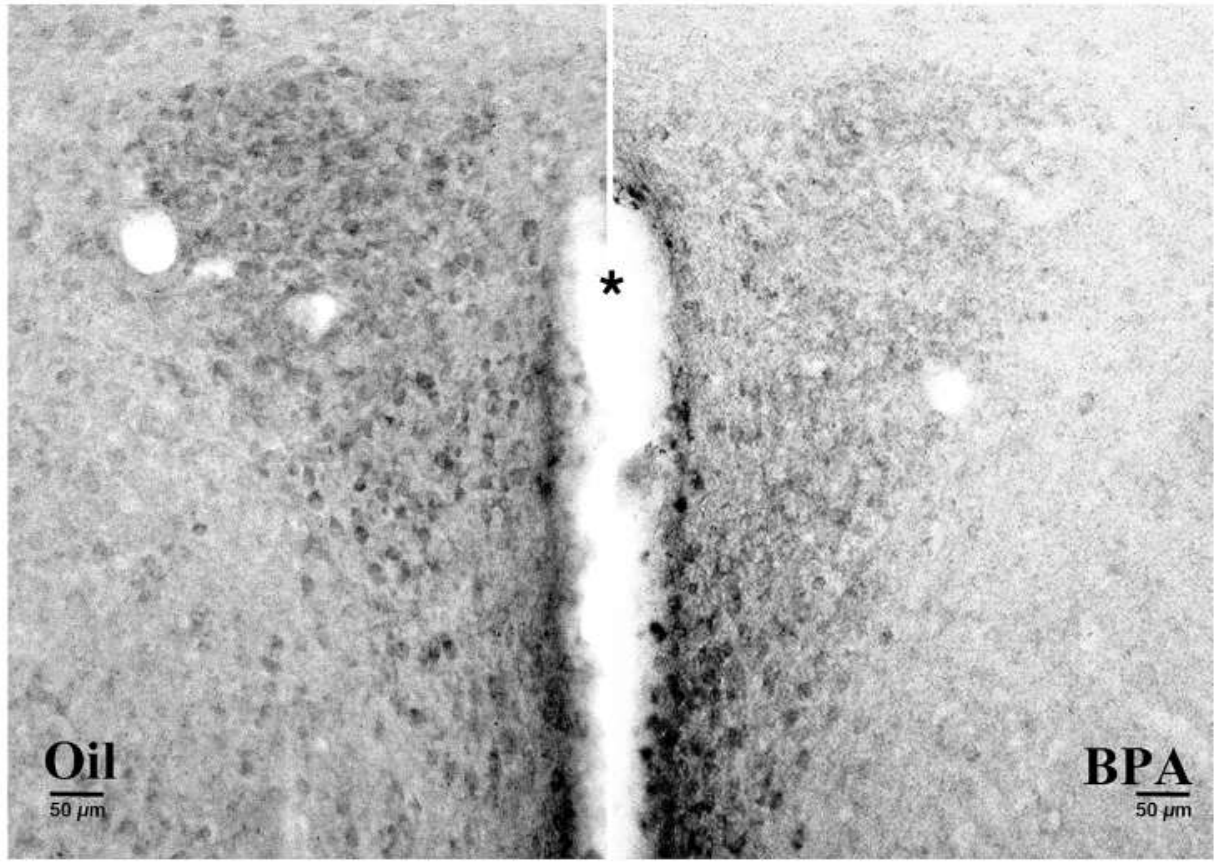

B

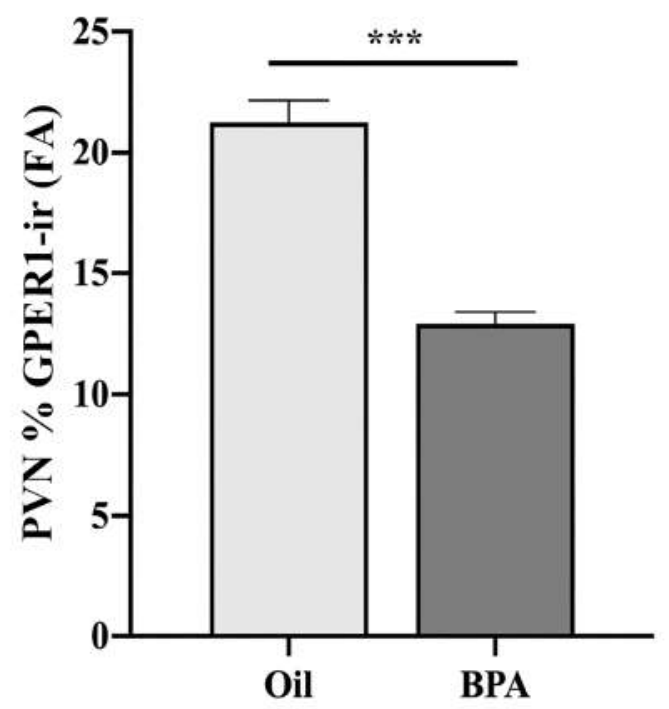

C

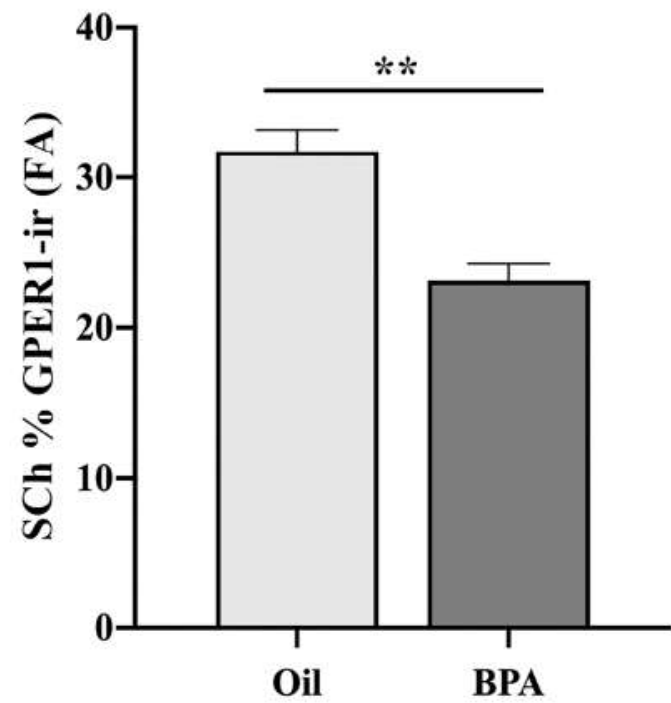

Figure 4. GPER1-ir in the PVN and SCh of oil-treated and BPA-treated dams. A) Representative images of GPER1-ir in a coronal section of PVN of oil-treated (left image) or BPA-treated (right image) dams. Analysis of GPER1-ir, expressed as fractional area (FA), revealed a significant reduction in BPA-treated dams (dark gray) compared to the control ones (light gray), both in PVN (B) and in SCh (C). Data are expressed as mean \pm SEM. One-way ANOVA revealed a significant effect of the treatment for $p \leq 0.05$. GPER1, G protein-coupled estrogen receptor 1; PVN, paraventricular nucleus; SCh, suprachiasmatic nucleus; FA, fractional area; ${ }^{*}$ third ventricle. 
main target systems underlying the alterations observed in social behavior after exposure to different types of EDCs; $;^{19,47}$ nevertheless these abilities of environmental chemicals, including BPA, to alter nonapeptide signaling is poorly documented. Our analysis highlighted a decrease of AVP-ir in some of the analyzed hypothalamic nuclei of BPA-treated dams, but not for OXT-ir.

OXT plays a central role in the control of aggression, anxiety, pair and social bonding especially in females..$^{10,48,49}$ Nevertheless, we did not find any alterations in all the analyzed nuclei. Although the potential for BPA to disrupt the OXT-OXT receptor systems has previously been shown, the performed treatments were different from ours, in terms of dose, animal model, period of exposure and way of administration. ${ }^{50}$ Moreover, the OXT system is highly dynamic, it is therefore possible that the effects of BPA could be different depending on brain region, gender and age.

We detected significant alterations of the AVP expression in the SCh and in the PVN. In fact, in both nuclei, BPA-treated dams showed a significant decrease of AVP-ir in terms of both number of cells and fractional area. Although it is not yet fully clear how exposure to BPA can directly influence the reduction in the number of cells expressing AVP in the SCh and in the PVN, it is conceivable that chronic exposure to BPA induces a chronic, direct or indirect, modulation of the AVP system. BPA is a xenoestrogen and thanks to its structure can pass the blood brain barrier and bind estrogen receptors exerting multiple effects. ${ }^{51}$ AVP positive cells located in the SCh and in the PVN express estrogen receptors. ${ }^{52,53}$ In vitro studies showed that estradiol, acting through ER $\beta$ and GPER1, induces a downregulation of AVP expression. ${ }^{54-56}$ Thus, BPA can possibly mediate a direct downregulation of AVP expression through this pathway. Furthermore, the ability of BPA to alter estrous cycle is well known in the literature. ${ }^{57,58}$ In fact, we also have observed a significant increase in the time spent in estrus phase in our BPA-treated females. Longer time spent in estrus, together with altered level of circulating estradiol, could be partially responsible to indirect modulation of BPA through estrogen receptor on AVP expression in SCh and PVN.

The SCh is involved in the regulation and maintenance of circadian rhythms. ${ }^{59}$ In the literature, numerous studies show how prolonged exposure to BPA affects the homeostasis of this system. ${ }^{60}$ Levels of circulating sex steroid hormones are responsible to the modulation of circadian rhythms and particularly of circadian locomotor rhythms and estrus phase is associated with higher locomotor activity in rodents. ${ }^{61}$ Therefore, the persistence of estrus could be responsible of the higher distance traveled by our BPAtreated mice. Nevertheless, alterations in locomotor activity are considered as marker of altered stress response. ${ }^{62}$ Stress responses are integrated and regulated at PVN level involving AVP and corticotropin-releasing hormone $(\mathrm{CRH})$ neurons. ${ }^{63}$ In physiological conditions, following exposure to stress stimuli, there is an increase in the AVP mRNA levels in the PVN with consequent excitation of the entire hypothalamic-pituitary axis (HPA) ${ }^{64}$ Chronic exposures to different type of stress stimuli, including exposure to BPA, alter the homeostasis of the stress axis by influencing its inactivation, for example through changes in the stability of the AVP mRNA, causing its anticipated degradation and an incorrect signaling mechanism. ${ }^{65}$

In rodents, GPER1 is strongly expressed in PVN and $\mathrm{SCh},{ }^{66}$ with a high co-expression with vasopressin neurons, ${ }^{56,66}$ and is involved in the control of a variety of behaviors, including the social one. ${ }^{67,68}$ Interestingly, it is known that BPA displays low affinity for ER $\beta$ and high affinity for GPER $1 .{ }^{69}$ The analysis within these nuclei, which displayed significant AVP-ir alteration, highlighted significant effect also on GPER1-ir. In fact, it shown a significant reduction in GPER1-ir in BPA-treated dams compared to the control ones. Although GPER1 seems to be involved in rapid change of both AVP-ir and social behavior, ${ }^{56,67}$ in our study we showed effects of long-term exposure to BPA on its expression. This response can be due to down-regulation mechanisms, which often follow the desensitization of the receptor caused by repeated or chronic administrations. ${ }^{70}$ GPER 1 could be involved at first in the down regulation of AVP-ir and then could go through downregulation mechanisms itself.

In conclusion, our results support the idea that pregnancy represents a critical period in adulthood for endocrine disruption. In fact, the exposure to BPA may pose a risk even in adulthood (given the long-term exposure period, the persistence of these compounds in the environment and the ability of bisphenols to accumulate in certain compartments of the body). In particular, we showed that chronic exposure to low-dose BPA in adult female mice led to long-term alterations in both social behavior and a decrease of the vasopressin system in PVN and SCh, along with decreased expression of GPER1 within the same nuclei. These findings could be explained as BPA direct and indirect effects at central level, which could, finally, be partially linked to alterations in the behavioral outcome.

\section{Acknowledgements}

This work has been supported by Ministero dell'Istruzione, dell'Università e della Ricerca - MIUR project Dipartimenti di Eccellenza 2018-2022 to Department of Neuroscience Rita Levi Montalcini; Cavalieri-Ottolenghi Foundation, Orbassano, Italy; University of Turin, RiLo to GCP, SG. MM was a fellow of Prof. G.C. Bergui (2020) and is now a fellow of the Fondazione Umberto Veronesi (2021).

\section{References}

1. Frye CA, Bo E, Calamandrei G, Calza L, Dessi-Fulgheri F, Fernandez M, et al. Endocrine disrupters: a review of some sources, effects, and mechanisms of actions on behaviour and neuroendocrine systems. J Neuroendocrinol 2012;24:144-59.

2. Catenza CJ, Farooq A, Shubear NS, Donkor KK. A targeted review on fate, occurrence, risk and health implications of bisphenol analogues. Chemosphere 2021;268:129273.

3. Lehmler HJ, Liu B, Gadogbe M, Bao W. Exposure to bisphenol A, bisphenol F, and bisphenol $\mathrm{S}$ in U.S. adults and children: The national health and nutrition examination survey 20132014. ACS Omega 2018;3:6523-32.

4. Bonaldo B, Marraudino M, Casile A, Bettarelli M, Gotti S, Panzica GC. Effects of chronic exposure to Bisphenol-A in pregnant female mice. In: Proceedings 30th National Conference of the Italian Group for the Study of Neuromorphology, Turin, 2020. Eur J Histochem 2020;64:3200.

5. MacKay H, Abizaid A. A plurality of molecular targets: The receptor ecosystem for bisphenol-A (BPA). Horm Behav 2018;101:59-67.

6. Murata M, Kang JH. Bisphenol A (BPA) and cell signaling pathways. Biotechnol Adv 2018;36:311-27.

7. Marraudino M, Bonaldo B, Farinetti A, Panzica G, Ponti G, Gotti S. Metabolism disrupting chemicals and alteration of neuroendocrine circuits controlling food intake and energy metabolism. Front Endocrinol (Lausanne) 2019;9:766.

8. Street ME, Angelini S, Bernasconi S, Burgio E, Cassio A, Catellani $\mathrm{C}$, et al. Current knowledge on endocrine disrupting 
chemicals (EDCs) from animal biology to humans, from pregnancy to adulthood: Highlights from a National Italian Meeting. Int J Mol Sci 2018;19:1647.

9. Abel JL, Rissman EF. Location, location, location: Genetic regulation of neural sex differences. Rev Endocr Metab Disord 2012;13:151-61.

10. Bosch OJ, Neumann ID. Both oxytocin and vasopressin are mediators of maternal care and aggression in rodents: from central release to sites of action. Horm Behav 2012;61:293303.

11. Keller M, Vandenberg LN, Charlier TD. The parental brain and behavior: A target for endocrine disruption. Front Neuroendocrinol 2019;54:100765.

12. Neumann ID, Landgraf R. Balance of brain oxytocin and vasopressin: implications for anxiety, depression, and social behaviors. Trends Neurosci 2012;35:649-59.

13. Caldwell HK. Oxytocin and vasopressin: Powerful regulators of social behavior. Neuroscientist 2017;23:517-28.

14. Dumais KM, Veenema AH. Vasopressin and oxytocin receptor systems in the brain: Sex differences and sex-specific regulation of social behavior. Front Neuroendocrinol 2016;40:1-23.

15. Smith CJW, DiBenedictis BT, Veenema AH. Comparing vasopressin and oxytocin fiber and receptor density patterns in the social behavior neural network: Implications for cross-system signaling. Front Neuroendocrinol 2019;53:100737.

16. Panzica GC, Mura E, Pessatti M, Viglietti Panzica C. Early embryonic administration of xenoestrogens alters vasotocin system and male sexual behavior of the Japanese quail. Domest Anim Endocrin 2005;29:436-45.

17. Panzica GC, Viglietti-Panzica C, Mura E, Quinn Jr MJ, Palanza P, Ottinger MA. Effects of xenoestrogens on the differentiation of behaviorally relevant neural circuits. Front Neuroendocrinol 2007;28:179-200.

18. Gore AC, Krishnan K, Reilly MP. Endocrine-disrupting chemicals: Effects on neuroendocrine systems and the neurobiology of social behavior. Horm Behav 2019;111:7-22.

19. Patisaul HB. Endocrine disruption of vasopressin systems and related behaviors. Front Endocrinol (Lausanne) 2017;8:134.

20. Marraudino M, Carrillo B, Bonaldo B, Llorente R, Campioli E, Garate I, et al. G Protein-coupled estrogen receptor immunoreactivity in the rat hypothalamus is widely distributed in neurons, astrocytes, and oligodendrocytes, fluctuates during the estrous cycle, and is sexually dimorphic. Neuroendocrinology 2021;111:660-77.

21. Palanza PL, Howdeshell KL, Parmigiani S, vom Saal FS. Exposure to a low dose of bisphenol A during fetal life or in adulthood alters maternal behavior in mice. Environ Health Perspect 2002; 110:415-22.

22. Bo E, Farinetti A, Marraudino M, Sterchele D, Eva C, Gotti S, et al. Adult exposure to tributyltin affects hypothalamic neuropeptide Y, Y1 receptor distribution, and circulating leptin in mice. Andrology 2016;4:723-34.

23. McLean AC, Valenzuela N, Fai S, Bennett SAL. Performing vaginal lavage, crystal violet staining, and vaginal cytological evaluation for mouse estrous cycle staging identification. J Vis Exp 2012;67:e4389.

24. Chang YC, Cole TB, Costa LG. Behavioral phenotyping for autism spectrum disorders in mice. Curr Protoc Toxicol 2017;72:11.22.1-21.

25. Marraudino M, Miceli D, Farinetti A, Ponti G, Panzica G, Gotti S. Kisspeptin innervation of the hypothalamic paraventricular nucleus: sexual dimorphism and effect of estrous cycle in female mice. J Anat 2017;230:775-86.

26. Paxinos G, Franklin KBJ. The mouse brain in stereotaxic coordinates. 2nd ed. San Diego: Academic Press; 2001.
27. Watson RE Jr., Wiegand SJ, Clough RW, Hoffman GE. Use of cryoprotectant to maintain long-term peptide immunoreactivity and tissue morphology. Peptides 1986;7:155-9.

28. Ponti G, Rodriguez-Gomez A, Farinetti A, Marraudino M, Filice F, Foglio B, et al. Early postnatal genistein administration permanently affects nitrergic and vasopressinergic systems in a sex-specific way. Neuroscience 2017;346:203-15.

29. Sofroniew MV, Madler M, Müller OA, Scriba PC. A method for the consistent production of high quality antisera to small peptide hormones. Z Anal Chem 1978;290:163.

30. Sofroniew MV, Weindl A. Projections from the parvocellular vasopressin- and neurophysin-containing neurons of the suprachiasmatic nucleus. Am J Anat 1978;153:391-429.

31. Bean JC, Lin TW, Sathyamurthy A, Liu F, Yin DM, Xiong WC, et al. Genetic labeling reveals novel cellular targets of schizophrenia susceptibility gene: distribution of GABA and nonGABA ErbB4-positive cells in adult mouse brain. J Neurosci 2014;34:13549-66.

32. Villanueva C, Jacquier S, de Roux N. DLK1 is a somato-dendritic protein expressed in hypothalamic arginine-vasopressin and oxytocin neurons. PLoS One 2012;7:e36134.

33. Grassi D, Lagunas N, Pinos H, Panzica G, Garcia-Segura LM, Collado P. NADPH-diaphorase colocalizes with GPER and is modulated by the GPER agonist G1 in the SON and PVN of ovariectomized female rats. Neuroendocrinology 2017;104:94-104.

34. Hayward JN, Pavasuthipaisit K, Perez-Lopez FR, Sofroniew MV. Radioimmunoassay of arginine vasopressin in Rhesus monkey plasma. Endocrinology 1976;98:975-81.

35. Sawyer HR, Moeller CL, Kozlowski GP. Immunocytochemical localization of neurophysin and oxytocin in ovine corpora lutea. Biol Reprod 1986;34:543-8.

36. Ruiz-Palmero I, Hernando M, Garcia-Segura LM, Arevalo MA. G protein-coupled estrogen receptor is required for the neuritogenic mechanism of 17 beta-estradiol in developing hippocampal neurons. Mol Cell Endocrinol 2013;372:105-15.

37. Viglietti-Panzica C, Aste N, Balthazart J, Panzica GC. Vasotocinergic innervation of sexually dimorphic medial preoptic nucleus of the male Japanese quail: influence of testosterone. Brain Res 1994;657:171-84.

38. Wolstenholme JT, Taylor JA, Shetty SR, Edwards M, Connelly JJ, Rissman EF. Gestational exposure to low dose bisphenol A alters social behavior in juvenile mice. PLoS One 2011;6:e25448.

39. Patisaul HB. Achieving CLARITY on bisphenol A, brain and behaviour. J Neuroendocrinol 2020;32:e12730.

40. Prins GS, Patisaul HB, Belcher SM, Vandenberg LN. CLARITY-BPA academic laboratory studies identify consistent low-dose Bisphenol A effects on multiple organ systems. Basic Clin Pharmacol Toxicol 2019;125:14-31.

41. Vandenberg LN, Hunt PA, Gore AC. Endocrine disruptors and the future of toxicology testing - lessons from CLARITY-BPA. Nat Rev Endocrinol 2019;15:366-74.

42. Kumar D, Thakur MK. Anxiety like behavior due to perinatal exposure to bisphenol-A is associated with decrease in excitatory to inhibitory synaptic density of male mouse brain. Toxicology 2017;378:107-13.

43. Xu X, Dong F, Yang Y, Wang Y, Wang R, Shen X. Sex-specific effects of long-term exposure to bisphenol-A on anxiety- and depression-like behaviors in adult mice. Chemosphere 2015;120:258-66.

44. Naule L, Picot M, Martini M, Parmentier C, Hardin-Pouzet H, Keller M, et al. Neuroendocrine and behavioral effects of maternal exposure to oral bisphenol $\mathrm{A}$ in female mice. $\mathrm{J}$ Endocrinol 2014;220:375-88. 
45. Picot M, Naule L, Marie-Luce C, Martini M, Raskin K, Grange-Messent V, et al. Vulnerability of the neural circuitry underlying sexual behavior to chronic adult exposure to oral bisphenol a in male mice. Endocrinology 2014;155:502-12.

46. Wolstenholme JT, Goldsby JA, Rissman EF. Transgenerational effects of prenatal bisphenol A on social recognition. Horm Behav 2013;64:833-9.

47. Panzica GC, Bo E, Martini MA, Miceli D, Mura E, VigliettiPanzica $C$, et al. Neuropeptides and enzymes are targets for the action of endocrine disrupting chemicals in the vertebrate brain. J Toxicol Environ Health B Crit Rev 2011;14:449-72.

48. Neumann ID. Brain oxytocin: a key regulator of emotional and social behaviours in both females and males. J Neuroendocrinol 2008;20:858-65.

49. Heinrichs M, Domes G. Neuropeptides and social behaviour: effects of oxytocin and vasopressin in humans. Prog Brain Res 2008; 170:337-50.

50. Witchey SK, Fuchs J, Patisaul HB. Perinatal bisphenol A (BPA) exposure alters brain oxytocin receptor (OTR) expression in a sex- and region- specific manner: A CLARITY-BPA consortium follow-up study. Neurotoxicology 2019;74:13948.

51. Rubin BS. Bisphenol A: an endocrine disruptor with widespread exposure and multiple effects. J Steroid Biochem Mol Biol 2011;127:27-34.

52. Kanaya M, Higo S, Ozawa H. Neurochemical characterization of neurons expressing estrogen receptor beta in the hypothalamic nuclei of rats using in situ hybridization and immunofluorescence. Int J Mol Sci 2019;21:115.

53. Vida B, Hrabovszky E, Kalamatianos T, Coen C, Liposits Z, Kalló I. Oestrogen receptor alpha and beta immunoreactive cells in the suprachiasmatic nucleus of mice: distribution, sex differences and regulation by gonadal hormones. J Neuroendocrinol 2008;20:1270-7.

54. Grassi D, Bellini MJ, Acaz-Fonseca E, Panzica G, GarciaSegura LM. Estradiol and testosterone regulate arginine-vasopressin expression in SH-SY5Y human female neuroblastoma cells through estrogen receptors-alpha and -beta. Endocrinology 2013;154:2092-100.

55. Grassi D, Ghorbanpoor S, Acaz-Fonseca E, Ruiz-Palmero I, Garcia-Segura LM. The selective estrogen receptor modulator raloxifene regulates arginine-vasopressin gene expression in human female neuroblastoma cells through $\mathrm{G}$ protein-coupled estrogen receptor and ERK signaling. Endocrinology 2015;1563706-16.

56. Lagunas N, Marraudino M, de Amorim M, Pinos H, Collado P, Panzica G, et al. Estrogen receptor beta and G protein-coupled estrogen receptor 1 are involved in the acute estrogenic regulation of arginine-vasopressin immunoreactive levels in the supraoptic and paraventricular hypothalamic nuclei of female rats. Brain Res 2019;1712:93-100.
57. Rattan S, Zhou C, Chiang C, Mahalingam S, Brehm E, Flaws JA. Exposure to endocrine disruptors during adulthood: consequences for female fertility. J Endocrinol 2017;233:R109-29.

58. Lopez-Rodriguez D, Franssen D, Sevrin E, Gerard A, Balsat C, Blacher S, et al. Persistent vs transient alteration of folliculogenesis and estrous cycle after neonatal vs adult exposure to bisphenol A. Endocrinology 2019;160:2558-72.

59. Hastings MH, Maywood ES, Brancaccio M. Generation of circadian rhythms in the suprachiasmatic nucleus. Nat Rev Neurosci 2018;19:453-69.

60. Zheng X, Zhang K, Zhao Y, Fent K. Environmental chemicals affect circadian rhythms: An underexplored effect influencing health and fitness in animals and humans. Environ Int 2021;149:106159.

61. Hatcher KM, Royston SE, Mahoney MM. Modulation of circadian rhythms through estrogen receptor signaling. Eur J Neurosci 2020;51:217-28.

62. Liu J, Scira J, Donaldson S, Kajiji N, Dash GH, Donaldson ST. Sex and trait anxiety differences in psychological stress are modified by environment. Neuroscience 2018;383:178-90.

63. Daviu N, Fuzesi T, Rosenegger DG, Rasiah NP, Sterley TL, Peringod G, et al. Paraventricular nucleus CRH neurons encode stress controllability and regulate defensive behavior selection. Nat Neurosci 2020;23:398-410.

64. Biag J, Huang Y, Gou L, Hintiryan H, Askarinam A, Hahn JD, et al. Cyto- and chemoarchitecture of the hypothalamic paraventricular nucleus in the C57BL/6J male mouse: a study of immunostaining and multiple fluorescent tract tracing. J Comp Neurol 2012;520:6-33

65. Panagiotidou E, Zerva S, Mitsiou DJ, Alexis MN, Kitraki E. Perinatal exposure to low-dose bisphenol A affects the neuroendocrine stress response in rats. $\mathrm{J}$ Endocrinol 2014;220:207-18.

66. Hadjimarkou MM, Vasudevan N. GPER1/GPR30 in the brain: Crosstalk with classical estrogen receptors and implications for behavior. J Steroid Biochem Mol Biol 2018;176:57-64.

67. Ervin KS, Lymer JM, Matta R, Clipperton-Allen AE, Kavaliers $\mathrm{M}$, Choleris E. Estrogen involvement in social behavior in rodents: Rapid and long-term actions. Horm Behav 2015;74:53-76.

68. Ervin KS, Mulvale E, Gallagher N, Roussel V, Choleris E. Activation of the $\mathrm{G}$ protein-coupled estrogen receptor, but not estrogen receptor alpha or beta, rapidly enhances social learning. Psychoneuroendocrinology 2015;58:51-66.

69. Acconcia F, Pallottini V, Marino M. Molecular mechanisms of action of BPA. Dose Response 2015;13:1559325815610582.

70. Rajagopal S, Shenoy SK. GPCR desensitization: Acute and prolonged phases. Cell Signal 2018;41:9-16.

Received for publication: 7 May 2021. Accepted for publication: 20 October 2021.

This work is licensed under a Creative Commons Attribution-NonCommercial 4.0 International License (CC BY-NC 4.0).

(C) Copyright: the Author(s), 2021

Licensee PAGEPress, Italy

European Journal of Histochemistry 2021; 65(s1):3272

doi:10.4081/ejh.2021.3272 